\title{
A new approach for multi-agent coalition formation and management in the scope of electricity markets
}

\author{
T. Pinto, H. Morais, P. Oliveira, Z. Vale, I. Praça, C. Ramos
}

\begin{abstract}

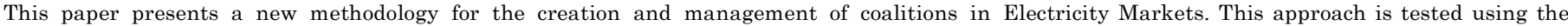

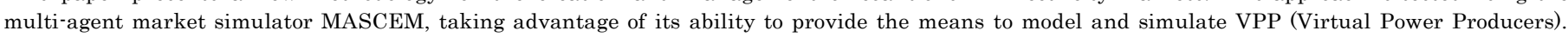

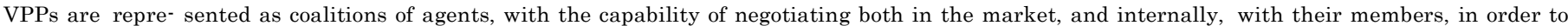
combine and manage their individual specific characteristics and goals, with the strategy and objectives of the VPP itself.

The new features include the development of particular individual facilitators to manage the communications amongst the members of each coalition independently from the rest of the simulation, and also the mechanisms for the classification of the agents that are candidates to join the coalition.

In addition, a global study on the results of the Iberian Electricity Market is performed, to compare and analyze different approaches for defining

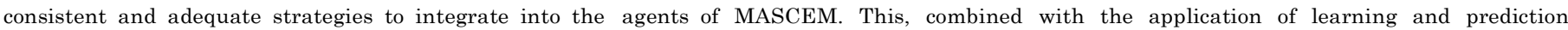

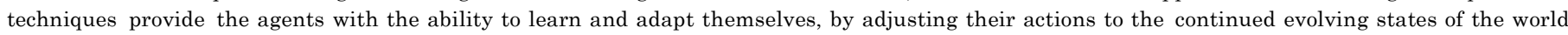
they are playing in.
\end{abstract}

Keywords:

Multi-agent systems, Virtual power producers, Distributed generation, Competitive electricity markets, Intelligent decision making, Agent negotiation strategies

\section{Introduction}

The recent restructuring of the energy markets, characterized by an enormous increase of the competition in this sector, led to relevant changes in the participating entities operation [1,2], which brought along some new problems and issues to be addressed. Some of the most important difficulties arise from the fact that the coordination between technical and economic issues is much more complex in the present context. Electricity market operation has to consider the physical constraints of power systems, market operation rules and financial issues.

Technical requirements of power systems are not always adequately addressed by electricity markets' rules. This is mainly due to two main factors: little experience in competitive electricity markets operation and the complexity of modelling relationships between power systems and electricity markets operation. This requires not only robust economic and financial background but also power system physics background. A clear understanding of the impact of power systems physics on market dynamics and viceversa is also required.
Real-world restructured electricity markets are sequential open-ended games with multiple participants trading for electric power on a daily basis. Market players and regulators are very interested in foreseeing market behaviour: regulators to test rules before they are implemented and detect market inefficiencies; market players to understand market behaviour and operate in order to maximize profits.

Each player acting in an Electricity Market has his own goals and should use adequate strategies in order to pursuit those goals, its strategic behaviour [3] being determinant for its success. A player's behaviour exhibits changes in response to new information and knowledge that he may have; this may refer to his self knowledge, to knowledge coming from the exterior and from the dynamic complex interactions of the heterogeneous individual entities.

In general, competitive environments, as is the present case of electricity markets, require good decision-support tools to assist players in their decisions. Relevant research is being undertaken in this field, namely in what concerns player modelling and simulation, strategic bidding and decision-support [4e8].

The problem is that, in the case of complex markets, the internal dynamics, due namely to players' strategic behaviour and interaction with each other, has to be considered. This is why AI (artificial intelligence) approaches, namely multi-agent systems, may give an important contribution for market modelling and simulation. 

Moreover, AI is also extremely important for providing market players with decision-support tools [9e11].

To explore and study different approaches in dealing with these issues, several modelling tools directed to the study of restructured wholesale power markets have emerged [12]. Some relevant tools in this domain are the "AMES Wholesale Power Market Test Bed" $[6,7]$ and "EMCAS e Electricity Market Complex Adaptive System" [13]. MASCEM e Multi-Agent Simulator for Electricity Markets $[3,4,14]$ is also a modelling tool that is being used to study restructured electricity markets.

MASCEM considers agents, representing the different independent entities in Electricity Markets, allowing them to establish their own objectives and decision rules. They have dynamic strategies that consider other agents' behaviour, learning from past situations and agents' past actions.

This paper focuses on the MASCEM agents' ability to adapt and act accordingly to the constantly evolving stages of the "world" in which they are meant to act on. So having in mind the present fierce competitive electricity markets, each day players need to find different and better ways to face market dynamics and pursuit their goals. In a scenario like the electricity markets players should predict what is to come to be better prepared for dealing with the changes. Considering that, different approaches in dealing with the markets must be tried, in order to obtain a better understanding of how to get the best results when negotiating in the market, being able to define adequate strategic behaviour [15e17]. Analysis and simulation studies are important to understand in what ways one and others' behaviour can affect the negotiations. This allows to focus on the negotiation strategies, and to understand how different ways of playing in the market can get us better results in different situations [3,4,18].

The paper presents several studies on the Iberian Electricity Market, where some predicting strategies are applied, in order to compare different approaches and decide on the best ways to improve the agents' capabilities to adapt and constantly adequate and refine their strategies [15e17].

The paper also addresses the inclusion of VPP (Virtual Power Players) models and simulation tools in the scope of MASCEM. VPPs represent the aggregation of a set of producers, mainly based on DG (distributed generation) and renewable sources. They can provide the means to adequately support the increasing use of DG and its participation in the context of competitive electricity markets.

VPPs are responsible for the management of the coalition of producers, including the role of negotiating in the energy market in behalf of the coalition, and negotiating internally with their members, to guarantee that the terms of each member's contracts are fair and suited to the VPPs characteristics and objectives. For that we also present a classification algorithm, which analyses each producer's characteristics and tests their suitability to the VPPs objectives. This process provides the VPP with the knowledge of which producers are most likely to favourably contribute to the VPPs' achievement of better results, and so allowing the VPP to decide which producers to aggregate or not in each moment.

This classification mechanism provides another great advantage; it allows the VPP to distribute the profits amongst its members with a fair basis, having in account the classification value that each member was awarded, in addition to the amounts of energy that it produced.

Section 2 presents an overview of MASCEM simulator, including the simulator's multi-agent model, and the implemented negotiation mechanisms. Section 3 deals with coalitions, in the context of multi-agent systems, detailing its use for VPP modelling in MASCEM, and describes the producers' classification mechanism. Section 4 presents a case study with several examples, where the new strategy proposals are analyzed, and finally Section 5 presents the most relevant conclusions of the paper, and the future developments to be implemented in the MASCEM simulator.

\section{MASCEM simulator}

MASCEM is a modelling and simulation tool that has been developed with the purpose of studying complex restructured electricity markets operation. It provides market players with simulation and decision-support resources, being able to give them a competitive advantage in the market.

As market players are complex entities, having their very own characteristics and objectives, making their decisions and interacting with other players, MASCEM was developed as a multi-agent based simulation tool, modelling the complex dynamic market players, including their interactions and medium/long-term gathering of data and experience. MASCEM uses game theory, machine learning techniques, scenario analysis and optimization techniques to model market agents and to provide them with decision-support $[3,19,20]$.

MASCEM's purpose is to be able to simulate as many market models and player types as possible so it can realistically reproduce the operation of real electricity markets. This enables it to be used not only as a simulation and decision-support tool for short/ medium term purposes, but also as a tool to support long-term decisions, such as the ones taken by regulators.

MASCEM includes several negotiation mechanisms usually found in electricity markets. MASCEM can simulate several types of markets, namely: Pool Markets, Bilateral Contracts, Balancing Markets and Forward Markets.

Forward contracts, which are a significant part of electricity trading, play a crucial role in the electricity market. These are contracts that fix prices now for electricity that will be supplied later, and enable speculation on future price development or hedging.

Power exchanges established the trade of forward and futures contracts early on and, by now, large volumes are being traded. A power forward contract is characterized by a fixed delivery price per MW, a delivery period and the total amount of energy to be delivered. One can observe that contracts with a long delivery period show less volatile prices than those with short delivery periods.

VPP Forward Market operation will be limited by the aggregated producers. If the VPP has many producers whose generation depends on natural resources, it is complicated to establish forward contracts because the guarantee of the energy supply is low.

In day-ahead electricity markets, electricity is traded for each hour, or mid-hour of the next day. The energy price in balancing markets can obviously be different from the day-ahead market price enabling the VPP to incur in losses or profits.

\subsection{MASCEM multi-agent model}

There are several entities involved in the negotiations in the scope of electricity markets; our multi-agent model represents all the involved entities and their relationships. MASCEM's multiagent model includes: a Market Facilitator Agent, Seller Agents, Buyer Agents, VPP (Virtual Power Producer) Agents, VPP Facilitator Agents, a Market Operator Agent and a System Operator Agent.

Fig. 1 presents the MASCEM global structure, with the representation of its most important entities and interactions.

In the simulation, the Market Facilitator acts as the coordinator of the market but it must be seen as a computational entity that does not represent a real entity playing in the market. It knows the identities of all the agents present in the market, regulates the negotiation process and assures the market is functioning 


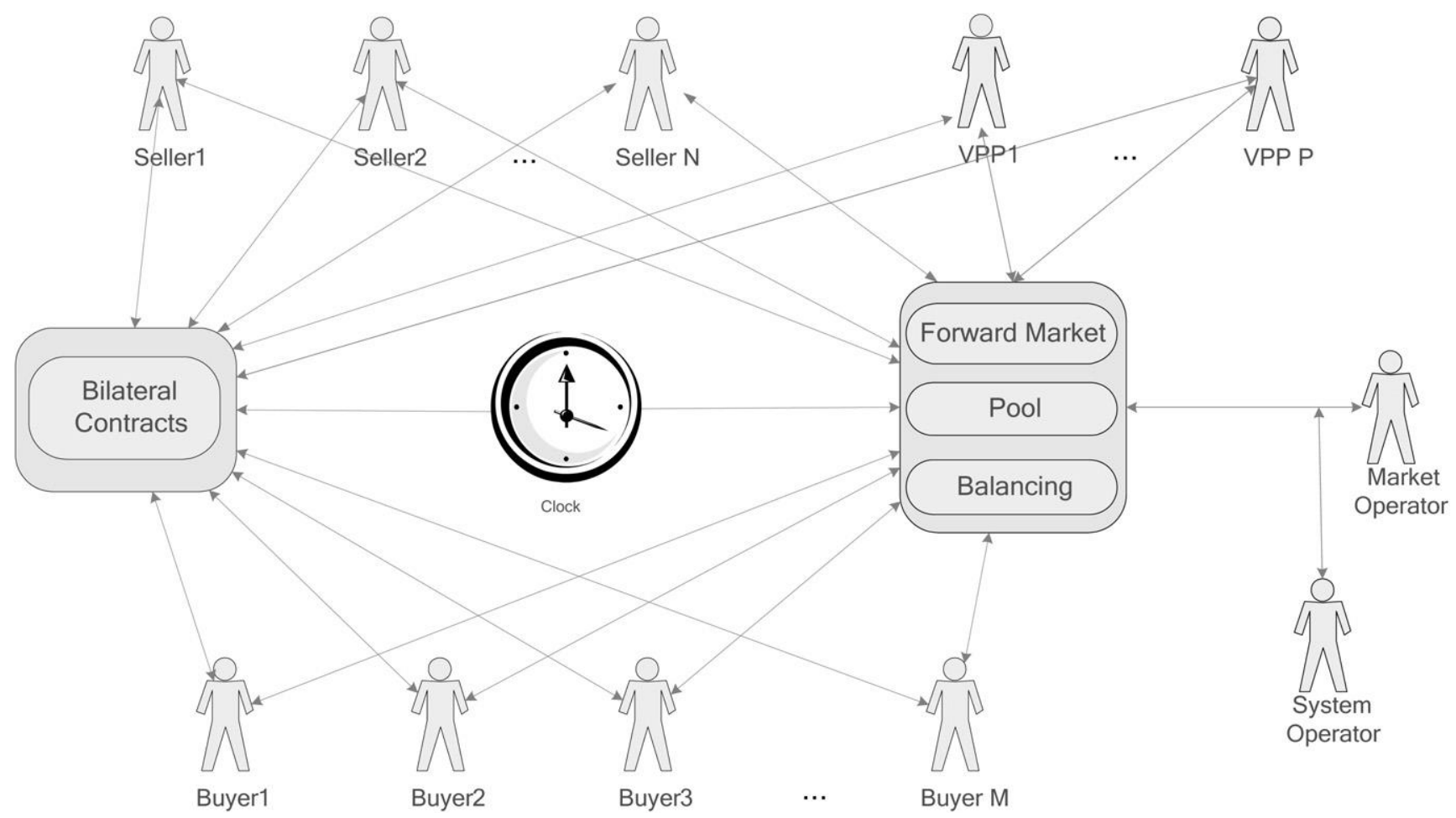

Fig. 1. MASCEM negotiation framework.

according to the established rules. The first step agents have to take to participate in the market is to register at the Market Facilitator, specifying their market role and services.

The System Operator Agent represents the entity that is responsible for the transmission grid and all the involved technical constraints. Every established contract, either through Bilateral Contracts or through the Pool, must be communicated to the System Operator, who analyses its technical feasibility from the Power System point of view.

The Market Operator Agent is responsible for the negotiation in the scope of a pool and by the resulting market clearing. This agent is only present in simulations of Pool or Hybrid markets. The Market Operator will receive bids from Sellers and Buyers, analyze them and determine the MCP (market clearing price) and accepted bids.

Seller and Buyer Agents are the two key players in the market. Sellers represent entities able to sell electricity in the market, e.g. companies holding electricity production units. Buyers may

represent electricity consumers or even distribution companies. The user, who must also specify his intrinsic and strategic characteristics, defines the number of Sellers and Buyers in each scenario.

Sellers will compete with each other, since each seller is interested in maximizing its profits. On the other hand, Sellers will cooperate with Buyers while trying to establish some agreement that is profitable for both. From this point of view, electricity markets are a very rich domain where it is possible to develop and test several algorithms and negotiation mechanisms for both cooperation and competition, coexisting in the same complex environment.

VPPs are special entities; they represent coalitions of producers that for some reason do not have the power or desire to negotiate in the market by themselves. This can be due to their small dimension and low production, or for strategic reasons. VPPs negotiate in the market by representing their aggregated members, and are seen by the market as regular sellers.
VPPs have the features of negotiating both in the market, and also internally, inside the coalition, with its members, in order to adequate the used strategies to their objectives and characteristics.

The VPP Facilitators support VPPs' business. They gather information about generation agents, both those who are playing in the market and those who are not. This information is relevant for VPP

business because some producers of reduced dimension cannot participate separately in the market, but can be associated to a VPP.

The VPP Facilitators manage the information between the

producers that are part of the coalition and the VPP in the VPP aggregation process and in its operation process. The VPP Facilitators inform the Market Facilitator about new agreements between producers and VPPs.

VPPs' integration in MASCEM and the developments that this inclusion implies are detailed in Section 3.

\subsection{MASCEM negotiation mechanisms}

On the basis of the results obtained in the past periods, Sellers and Buyers revise their strategies for the future. Seller and Buyer Agents have strategic behaviour to define their desired price. These agents have time-dependent strategies, and behaviour-dependent strategies, to define the price for the next day according to the results previously obtained.

To adjust price between days, also referred as behaviourdependent strategies, MASCEM provides two basic strategies: one called Composed Goal Directed and another called Adapted Derivative Following. These are important strategies that use the knowledge obtained with past experiences to define bid prices for next periods.

The Composed Goal Directed strategy is based on two consecutive objectives, according to each player objectives.

The Adapted Derivative Following strategy is based on a Derivative Following strategy proposed by Greenwald [21]. The Adapted Derivative Following strategy adjusts its price by looking to the 
amount of revenue earned in previous periods as a result of the previous pricechange.

According to each player model and knowledge, these strategies are composed with more specific strategies, giving place to specially tailored strategies for each agent. As an example, in the case of producers, the specific strategies take into account the generation technology. In the case of generation technologies based on renewable sources, highly dependent from weather factors, these are considered. For each player, all relevant strategies are composed, according to the player defined goals and to the identified situation. In this way, player strategic behaviour depends from several aspects, namely the following:

- player defined goals;

- player model (including technical characteristics);

- player knowledge (namely concerning other players' models);

- context (taking into account factors of different nature, including market regulation, external factors such as oil prices, weather, which are considered in the player model but also in a more general context, namely for load forecasting).

This approach makes players' strategies adaptive both to each player and to each situation.

One of our main goals is to provide MASCEM with the means to adapt itself to the surrounding constantly changing environment. At each moment MASCEM analyses the conditions of the world and the actions that should be more suitable in that context. To accomplish this goal, MASCEM analyses the world it is simulating (the electricity market), trying to understand how it is evolving at each moment, as well as the players that are operating in it.

One of the most important issues in adapting players' behaviour is providing them the means to correctly perceive which are the most advantageous decisions for them to perform, taking into account the characteristics of the players they interact with. This is our goal in defining coalition formation mechanisms according to players' data. Our proposal to do so is presented in the following section.

\section{Coalitions management}

\subsection{VPPs integration in MASCEM}

VPPs (Virtual Power Players) are multi-technology and multisite heterogeneous entities. Relationships among aggregated producers, VPPs and the remaining Electricity Market agents are a key factor for their success [22].

To sell energy in the market, VPPs must forecast the generation of the aggregated producers and "save" some power capacity to assure a reserve to compensate a generation oscillation of producers with technologies dependent on natural resources.

From the point of view of the multi-agent system, VPPs are seen as coalitions of agents, requiring specific procedures for coalition formation. Once a coalition is established, it can aggregate more agents or even discard some, depending on the established contracts. This model allows modelling the entire decision making concerning VPP formation and also subsequence aggregation of more producers.

To take decisions about these issues, VPPs have to detain knowledge related with the existing producers, which can eventually be aggregated. Decisions concerning VPP formation and aggregation of new producers result mainly from two distinct matters. On one hand, each VPP classifies the producers according to a set of criteria defined by itself. On the other hand, it establishes the goals of VPP formation or of aggregation of more producers, according to its operating strategies and to its necessities at the moment. Aggregation proposals are then elaborated in function of the resulting knowledge.

Once the VPP formation process is finished, the VPP needs to coordinate its operation. The VPP must place bids in the market, considering the contracts with its producers, the generation forecast, the reserves and its market strategy. However, as VPPs are themselves a set of other agents, there are some preliminary steps to define their bids.

Firstly, all the capacity available from the different aggregated distributed energy resources must be gathered to establish the electricity amount to trade on the market. The different generation costs must be analyzed to define the interval for envisaged proposals. This means VPP agents will have an utility function that aggregates all the involved units' characteristics. The analysis of the aggregated producers' proposals will be done according to each unit's capabilities and costs.

After the market session, the VPP agent undertakes an internal dispatch, analyzing and adjusting its generation and reserve to maximize profits and informs the aggregated producers about their dispatch.

Finally, in function of the generation, the used and unused reserve of each producer and the established contracts of the VPP fulfilment, the VPP determines the producers' remuneration [23].

The Introduction of VPP models in MASCEM required to re-think MASCEM architecture, namely in what concerns agent communication [14].

From a conceptual point of view, each VPP can be seen as an agent coalition (Fig. 2).

In Fig. 2 we can see, highlighted, the changes to the initial MASCEM structure, considering the integration of VPPs as new multi-agent systems with their own facilitators, inside the global architecture.

Modelling one agent coalition for each VPP requires not only modelling the agents that take part in each coalition, but also their interactions. These include interactions during distinct periods. In the pre-bidding period each VPP has to prepare the bids; after the clearance of the market, each VPP has to internally dispatch the sold energy.

As the overall performance of the market simulator must be optimized, these VPP internal interactions should only overload the whole simulation in the exact required measure.

Moreover, in order to make VPP coalitions act at their best performance the first step was to determine how to integrate them in the market negotiations with minimum degradation of the previous implementation performance.

This led to face each VPP as an individual multi-agent system, operating in the scope of the overall multi-agent system that simulates the electricity market. Considering each VPP as a multiagent system allows an interesting approach from both the performance and the conceptual point of view. In order to develop a computational implementation of this conceptual architecture, each VPP has to have its own facilitator, with no relation to the market facilitator, to coordinate the negotiations between the members of each individual VPP. This means that each VPP has its own facilitator that allows it to communicate with all the producers that are part of its coalition or intend to join it, independently from the remaining agents' communication.

\subsection{Coalition management/classification mechanism}

In order to asset the VPP with the capability to choose the most appropriate ways to manage its coalition, a classification structure that enables the VPP to choose the producers that are most adequate for the VPP's strategy and goals at each moment has been created. The VPP starts by defining its profile, including its 


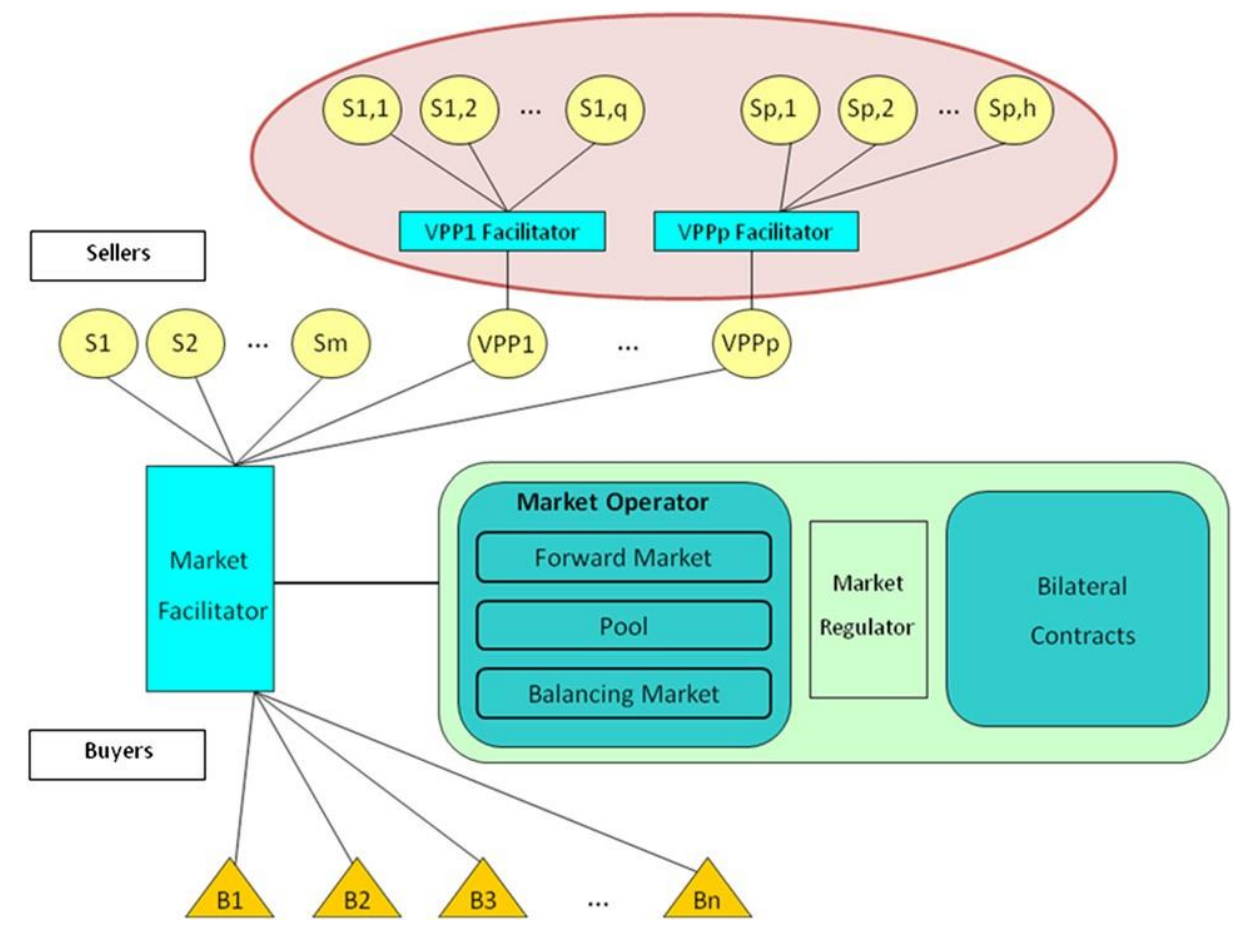

Fig. 2. MASCEM agent architecture with VPPs.

characteristics, and then, when a producer requests to join the coalition, it will be classified through a set of formulae that relate

the producers' and the VPP's characteristics. At each negotiation period the VPP will choose the best candidates to join the coalition.

The producers' selection criteria are different for each VPP, depending on the dimension and on the already aggregated producers. In MASCEM, VPPs are classified according to the following five different pre-established types:

- PVPP (Parallel VPP) e Includes different producers with distinct generation capacities, typically larger than $1 \mathrm{MW}$ and lower than $20 \mathrm{MW}$. The common characteristic of the VPPs of this type is their participation in parallel markets;

- LSVPP (Large Scale VPP) e Includes producers with large generation capacity, typically higher than $10 \mathrm{MW}$ and many producers with small capacity, typically lower than $2 \mathrm{MW}$;

- mVPP (Micro VPP) e This VPP type aggregates producers with very small capacity, typically lower than 1 MW;

- GVPP (Global VPP) e This type of VPP aggregates both producers and consumers, assuming the function of a trader;

- SVPP (Several VPP) e This VPP type does not have a priori defined characteristics so that it allows users to create more specific VPPs.

Decision making for VPP formation and subsequent aggregation of more producers takes into account a large set of producers' characteristics, such as the ones listed in the first column of Table 1. The weight of each of these characteristics depends on the VPP type, as shown in the subsequent columns of Table 1 . These weights are based on economic criteria and on VPP market strategies, and reflect the importance that each characteristic has to the VPP. So, as higher the value of the weight for a certain characteristic gets, the more suitable the candidate to join the VPP is required to be in what concerns that characteristic. The characteristics importance weights range from 0 to 10 . The values presented in Table 1 have been determined based on a set of a priori analyzed cases, considering possible VPP strategies and are used by MASCEM as default values. However MASCEM users can modify these values to adjust the VPP strategy according to their own needs.

The user also has the possibility of developing and simulating scenarios in which VPPs change their aggregated producers, in order to improve VPP strategy in function of market evolution.

The classification structure has been integrated with MASCEM with the purpose of being tested in an actual market simulator, and so allowing to derive conclusions about the efficiency of this procedure, and about the development of the behaviour of the VPPs when including such mechanisms. This new feature is a real added value to the intelligence of the VPP agents, by increasing their ability to take the best decisions when confronted with particular situations (in this case, the election of the producers who would be a greater asset to the coalition in the present and future, and contribute the most to the achievement of its objectives).

The mechanism has been implemented in LPA-Prolog and its integration in MASCEM has been done in the private facilitator of each VPP. The features of this new mechanism include:

Table 1

Producers' characteristics weights.

\begin{tabular}{lcclcc}
\hline Characteristics & PVPP & LSVPP & mVPP & GVPP & SVPP \\
\hline Speculative energy cost & 10 & 10 & 9 & 9 & 10 \\
Dispatchability & 7 & 9 & 7 & 10 & 7 \\
Reliability & 7 & 8 & 2 & 8 & 7 \\
Use of installed power & 5 & 7 & 2 & 5 & 5 \\
Lifespan & 3 & 3 & 1 & 3 & 5 \\
Volatility of prices & 7 & 8 & 3 & 7 & 7 \\
2nd Market & 9 & 4 & 4 & 6 & 5 \\
GHG emissions & 7 & 6 & 5 & 5 & 5 \\
Location & 4 & 2 & 8 & 6 & 5 \\
Dimension & 4 & 3 & 8 & 5 & 5 \\
Technology type & 5 & 5 & 6 & 6 & 5 \\
Social Impact & 5 & 5 & 5 & 4 & 5 \\
Maturity of technology & 4 & 5 & 2 & 4 & 5 \\
Commercial behaviour & 5 & 6 & 3 & 5 & 5 \\
\hline
\end{tabular}


Table 2

VPP's characteristics and tolerance factors.

\begin{tabular}{|c|c|c|c|c|c|}
\hline \multicolumn{3}{|l|}{ Characteristics } & \multirow{3}{*}{$\begin{array}{l}\text { VPP } 1 \\
\text { Large } \\
\text { Barcelona }\end{array}$} & \multirow{3}{*}{$\begin{array}{l}\text { VPP } 2 \\
\text { Global } \\
\text { Madrid }\end{array}$} & \multirow{3}{*}{$\begin{array}{l}\text { VPP } 3 \\
\text { Micro } \\
\text { Irun } \\
\end{array}$} \\
\hline & Type & & & & \\
\hline & Local & & & & \\
\hline \multirow[t]{12}{*}{ Objectives } & E.G. & Expected Cost (V/MWh) & 0.045 & 0.039 & 0.043 \\
\hline & A.F. & Average Failure (MWh) & $110^{*}$ & $110 *$ & $110^{*}$ \\
\hline & I.P.U. & Installed Power Use (hours) & 8000 & 7500 & 8500 \\
\hline & Reli. & Reliability (\%) & 97 & 90 & 85 \\
\hline & L.C. & Life Cycle (years) & 10 & 15 & 20 \\
\hline & Vol at. & Volatility (V/MWh) & 0.003 & 0.1 & 0.1 \\
\hline & Emis. & Emissions (g/MWh) & 0.3 & 0.1 & 0.1 \\
\hline & Dim. & Dimension (MW) & 20000 & 5000 & 200 \\
\hline & P.M.B.V. & Parallel Market Business Value (v) & $5000 *$ & $5000 *$ & $5000 *$ \\
\hline & E.M.B.V. & Electric Market Business Value (v) & $95000 *$ & $95000 *$ & $95000 *$ \\
\hline & P.M.R. & Parallel Market Remuneration (V/MWh) & $0.009 *$ & $0.009 *$ & $0.009^{*}$ \\
\hline & A.C.E. & Average Cost of Electricity (V/MWh) & $0.05^{*}$ & $0.05^{*}$ & $0.05^{*}$ \\
\hline Tolerance & E.C. & Expected cost & 20 & 10 & 10 \\
\hline \multirow[t]{13}{*}{ Factors $(0 e 20)$} & A.F. & Average Failure & 10 & 10 & 10 \\
\hline & I.P.U. & Installed Power Use & 5 & 10 & 15 \\
\hline & Reli. & Reliability & 5 & 10 & 15 \\
\hline & L.C. & Life Cycle & 5 & 10 & 15 \\
\hline & Vol at. & Volatility & 5 & 10 & 10 \\
\hline & Emis. & Emissions & 10 & 10 & 10 \\
\hline & Dim. & Dimension & 10 & 10 & 10 \\
\hline & T.Tec & Type of Technology & $0 * *$ & $0 * *$ & $0 * *$ \\
\hline & S.Imp. & Social Impact & $0 * *$ & $0^{* *}$ & $0 * *$ \\
\hline & Tec.M. & Technology Maturity & $0 * *$ & $0^{* *}$ & $0 * *$ \\
\hline & Local. & Localization & 20 & 20 & 20 \\
\hline & C.B. & Commercial Behaviour & $0 * *$ & $0 * *$ & $0 * *$ \\
\hline & S. M. & Second Market & 10 & 10 & 10 \\
\hline \multirow[t]{4}{*}{ Investments $(0 e 1)$} & Dim. & Dimension & 1 & 1 & 1 \\
\hline & T. Tec. & Type of Technology & 0 & 0 & 1 \\
\hline & Tec.M. & Technology Maturity & 1 & 1 & 0 \\
\hline & Local. & Localization & 1 & 0 & 0 \\
\hline
\end{tabular}

* Non Real Value; ** Not Used Values.

- The registration of new VPP types e There are five standard VPP a priori defined types. These VPP types present static factor weights, for an easier choice when a new VPP is created. Additionally, at the time of creation of a new VPP, the user has the choice of defining a new VPP type, defining the desired weights for the factors presented before. This allows the new VPP to be adapted to the specific objectives considered in each simulation;

- The classification of producers that intend to join the aggregation e A new producer that desires to be aggregated with a particular VPP must at a first instance provide all the data necessary for its classification concerning the VPP's characteristics, and constituents. Each producer that sendsits request for entering the VPP is awarded a classification;
- The acceptance or refusal of a producer application e Depending on the strategy adopted by each VPP, the applicant producers will be accepted or refused in the coalition. The acceptance process is based on a priori defined limit for the minimum classification for which the coalition will allow the new producer to be aggregated. Moreover, the VPP can also define a maximum number of members to be part of the coalition, refusing the entrance of all that apply when that number is reached.

When a new VPP is created in the simulator, it is required to define the various aspects that will characterize its objectives and desired orientation in the market. These factors and preferences will be the basis for the classification of each producer that intends

Table 3

Producers' data.

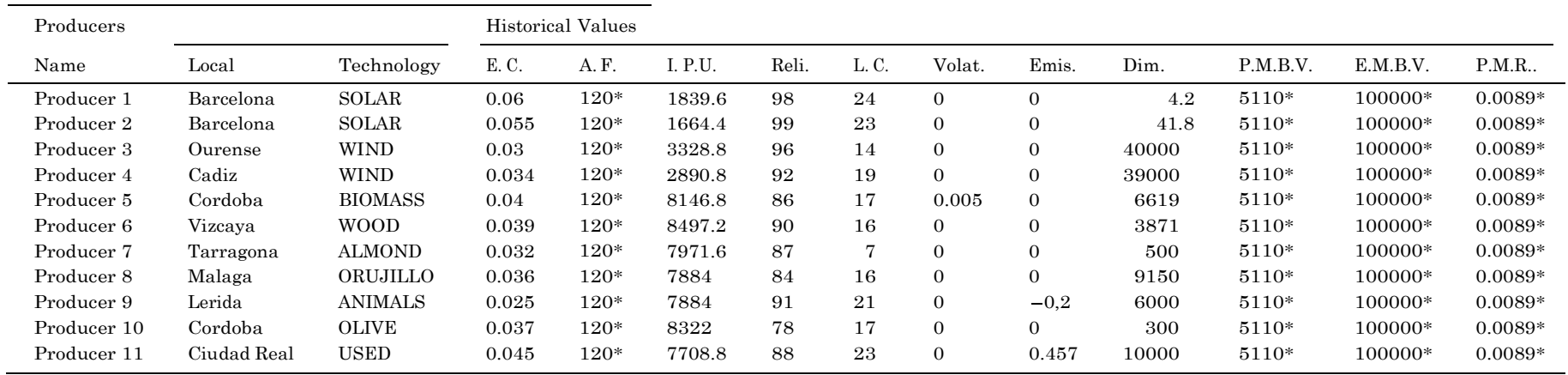


Table 4

Producers' classifications.

\begin{tabular}{|c|c|c|c|c|c|c|c|}
\hline \multirow{2}{*}{ Candidates } & \multicolumn{4}{|c|}{ Assigned Values } & \multicolumn{3}{|c|}{ Results } \\
\hline & T.Tec. & S.Imp. & Tec.M. & C.B. & Classification & Accepted & Status \\
\hline \multicolumn{8}{|c|}{ VPP1 } \\
\hline Producer 1 & 2 & 2 & 0 & 1 & 9.09 & Yes & Enter VPP \\
\hline Producer 2 & 2 & 2 & 0 & 2 & 9.21 & Yes & Enter VPP \\
\hline Producer 3 & 1 & 2 & -1 & 0 & 18.11 & Yes & Enter VPP \\
\hline Producer 4 & 1 & 2 & -1 & 2 & 21.96 & Yes & Enter VPP \\
\hline Producer 5 & 1 & 0 & 0 & 0 & 6.89 & Yes & Excluded \\
\hline \multicolumn{8}{|c|}{ VPP2 } \\
\hline Producer 2 & 2 & 2 & 0 & 1 & 6.97 & Yes & Excluded \\
\hline Producer 4 & 1 & 1 & -1 & 1 & 75.59 & Yes & Excluded \\
\hline Producer 6 & 0 & -2 & 1 & -2 & 13.18 & Yes & Enter VPP \\
\hline Producer 7 & 0 & 1 & -2 & -1 & 7.55 & Yes & Enter VPP \\
\hline Producer 8 & 2 & -2 & 2 & -1 & 23.08 & Yes & Enter VPP \\
\hline \multicolumn{8}{|c|}{ VPP3 } \\
\hline Producer 3 & 1 & 2 & -1 & 1 & 1152.65 & Yes & Excluded \\
\hline Producer 6 & 0 & -2 & 1 & -1 & 122 & Yes & Excluded \\
\hline Producer 9 & 1 & -2 & 1 & 1 & 200.91 & Yes & Enter VPP \\
\hline Producer 10 & 0 & -1 & -1 & 0 & 19.87 & Yes & Enter VPP \\
\hline Producer 11 & -1 & -1 & -1 & 0 & 266.43 & Yes & Enter VPP \\
\hline
\end{tabular}

to join this aggregation, together with the producer's individual characteristics. These characteristics are also required when a new producer is created.

Once a producer makes its application to join a certain VPP, all the information is sent to that VPP's facilitator, which will be responsible for its classification, and for the acceptance/refusal of the application. If it is accepted, that producer will be a member of the coalition from that point on.

Throughout each day the revenues from all the periods of negotiation must be distributed amongst the members of the aggregation.
To manage those transactions, the facilitator is also equipped with a profit distribution mechanism, which determines the amounts of payoff that the VPP members are going to receive.

This algorithm is based on the total amount of energy that the VPP was able to sell in each period; the market price for that period; and the amount of energy that each producer provided individually, along with the classification awarded by the VPP at the time of its entrance in the aggregation. The use of this mechanism ensures that the payoffs adequately reward the producers that are better classified, and those that produced the most in each period.

\section{Energy Market Transaction by Buyer}

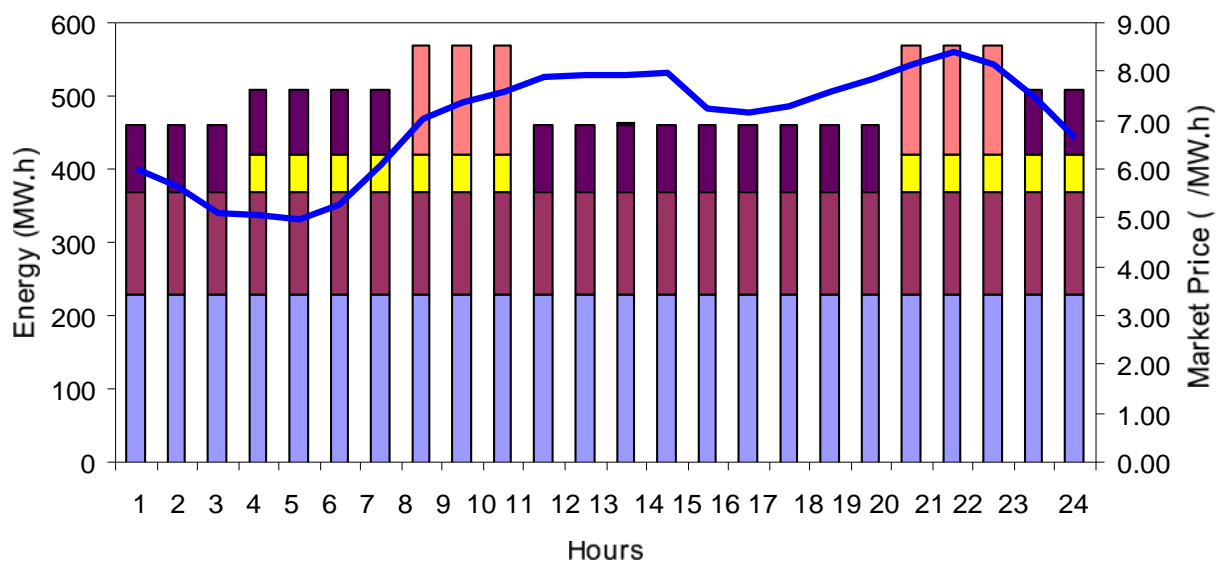

$\begin{array}{|llll|}\square \text { Buyer 1 } & \square \text { Buyer 2 } & \square \text { Buyer 3 } & \square \text { Buyer 4 } \\ \text { Buyer } 5 & \text { Buyer 6 } & \text { Buyer 7 } & \text { Market Price }\end{array}$

Fig. 3. Energy market transaction by buyer. 


\section{Energy Market Transaction by Seller}

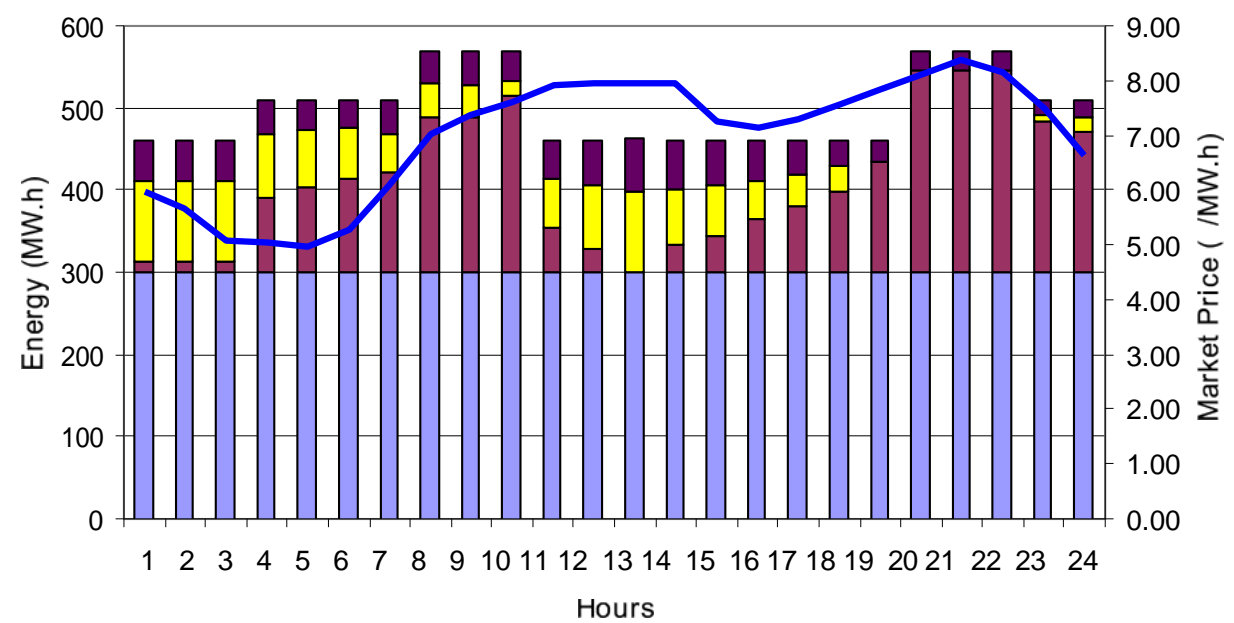

Hours

$\square$ Seller $1 \square$ Seller $2 \square$ Seller $3 \square$ VPP1 $\square$ VPP2 $\square$ Market Price

Fig. 4. Energy market transaction by seller.

The classification mechanism and the payoff distribution algorithm tests will be presented and discussed in the next section, using the VPP integration in MASCEM and the adjustment of the VPP facilitator to include the gathering and analysis of producers and the VPPs data.

\section{Case study}

The case study presented in this paper considers 11 seller agents, based on real producers of OMEL [24] (Spanish electricity market) with several technologies, together with 3 VPPs with distinct characteristics and strategies.

The main goal is that each VPP chooses the best producers to aggregate, according to its initial objectives. After this process is concluded, the agents will start the negotiation in the market, using distinct strategies, which allow studying their performance and taking some conclusions on those strategies which are better to be used by the agents in the future.

The results of VPP remuneration after each period of the market negotiations will also be presented to show how the profits distribution mechanism works, considering the members classification along with their individual production as the main factors to the determination of the individual revenues.

\subsection{Classification}

Table 2 characterizes the three VPPs considered in the case study, showing their objectives and tolerance factors. These factors, combined with the characteristics of each individual candidate producer, determine whether that producer will or not be accepted by the VPP.

Along with the factors presented in Table 2, the producers' data must be gathered in order to allow the classification to take place. Table 3 presents the data respective to each producer considered for this simulation. The abbreviations used in this table are presented in Table 2.

The Technology refers to the production type of each producer, while the Local is the localization of the production plant. Regarding the historical values, they are presented in the units referred in Table 2, taken from the historical information provided by OMEL.

\section{Sold Energy}

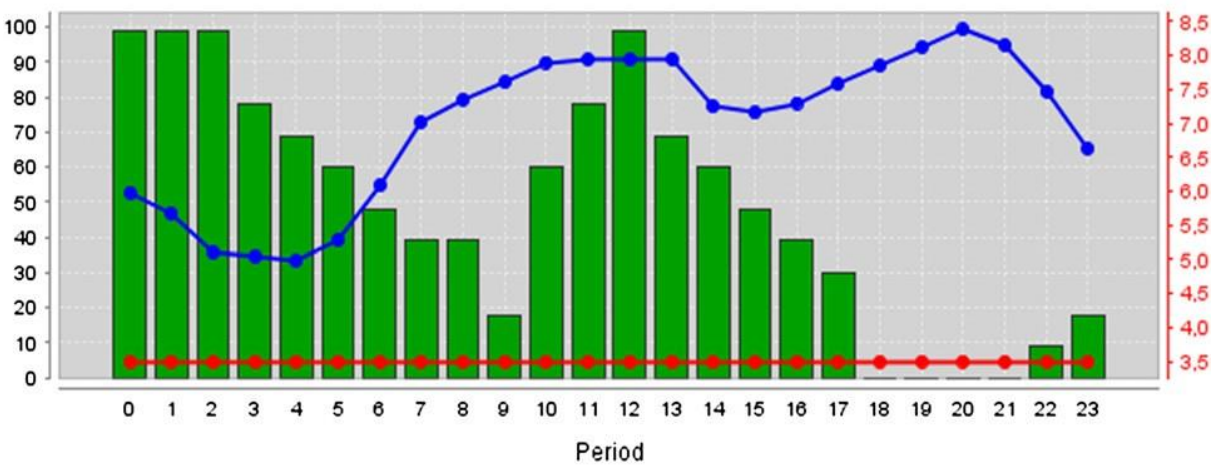

$\square \mathrm{BC} \square$ Pool $\square$ Unsold $\sim$ Price $\multimap$ Market Price 


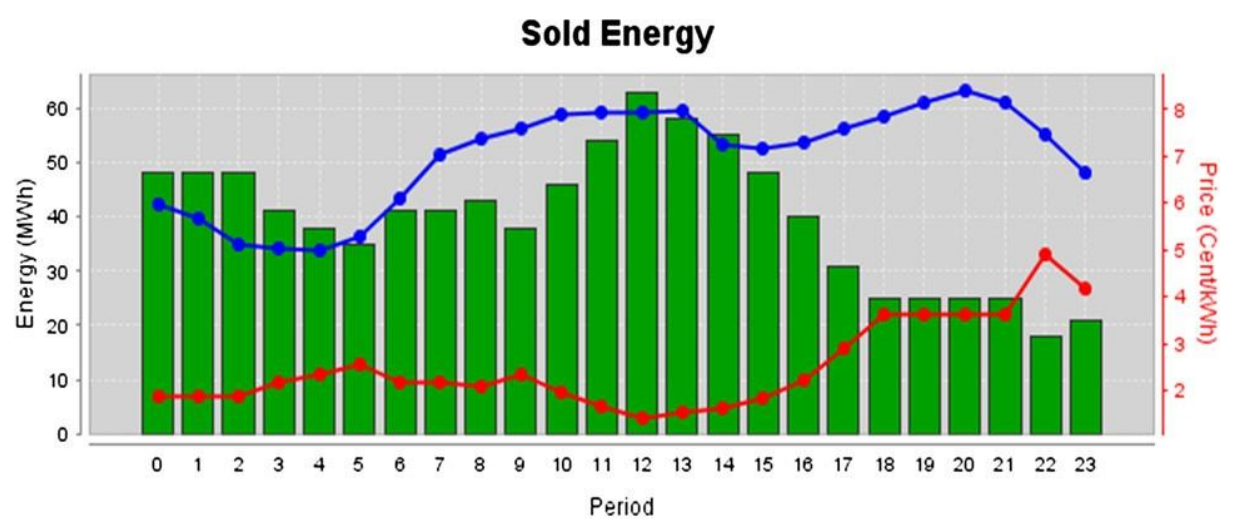

口 $\mathrm{BC} \square$ Pool $\square$ Unsold $\multimap$ Price $\bullet$ Market Price

Fig. 6. VPP2 results.

Using the proposed method for the classification, with the inputs being the historical values from the various producers, combined with the VPPs data shown before, originates the individual classification for each of the producers for each VPP, and consequent proposal results (entrance in the coalition accepted or not accepted). Table 4 shows the classification assigned to the producers that proposed to enter each aggregation. The abbreviations used in this table are presented in Table 2.

It can be seen in Table 4 that all the producers would have the entrance in the various aggregations guaranteed because the VPPs are initially empty and have positively classified all of them (although the profit a producer can provide is small, it is always higher than the null profit the VPP gets while being empty). As there are some producers that proposed entrance to more than one VPP, they will have to pass through a negotiation stage, to determine which producers will be assigned to each VPP.

\subsubsection{Entrance negotiation}

Once the classification process is finished, it is time to determine which of the producers will enter which of the VPPs. As all the producers obtained positive classifications for entrance in the three VPPs, the ones with the higher values for each of the three aggregations were selected, starting from VPP1, then VPP2 and finally VPP3, as this was the order of appliance by the producers.

In Table 4 it can be seen that VPP1 was awarded four members, as this VPP imposed the restriction of accepting at most four candidates. The ones assigned are those that obtained the higher scores of classification of all that proposed for entrance in this VPP. Those four producers are: Producer 1, Producer 2, Producer 3 and Producer 4, being Producer 5, for that reason, excluded. Afterwards, VPP2 aggregated Producer 6, Producer 7 and Producer 8, because the other two applicants were already assigned to the first VPP. Finally, VPP3 included Producers 9, 10 and 11; the ones that applied to this VPP and that were not yet assigned to other.

This version of the negotiation mechanism takes only into consideration the perspective of the VPP, by order of appliance. This mechanism is currently being improved to consider negotiation by both parts: VPPs and producers, allowing them to negotiate with several entities, and decide, based on the classifications and entrance conditions, the best deals from both perspectives.

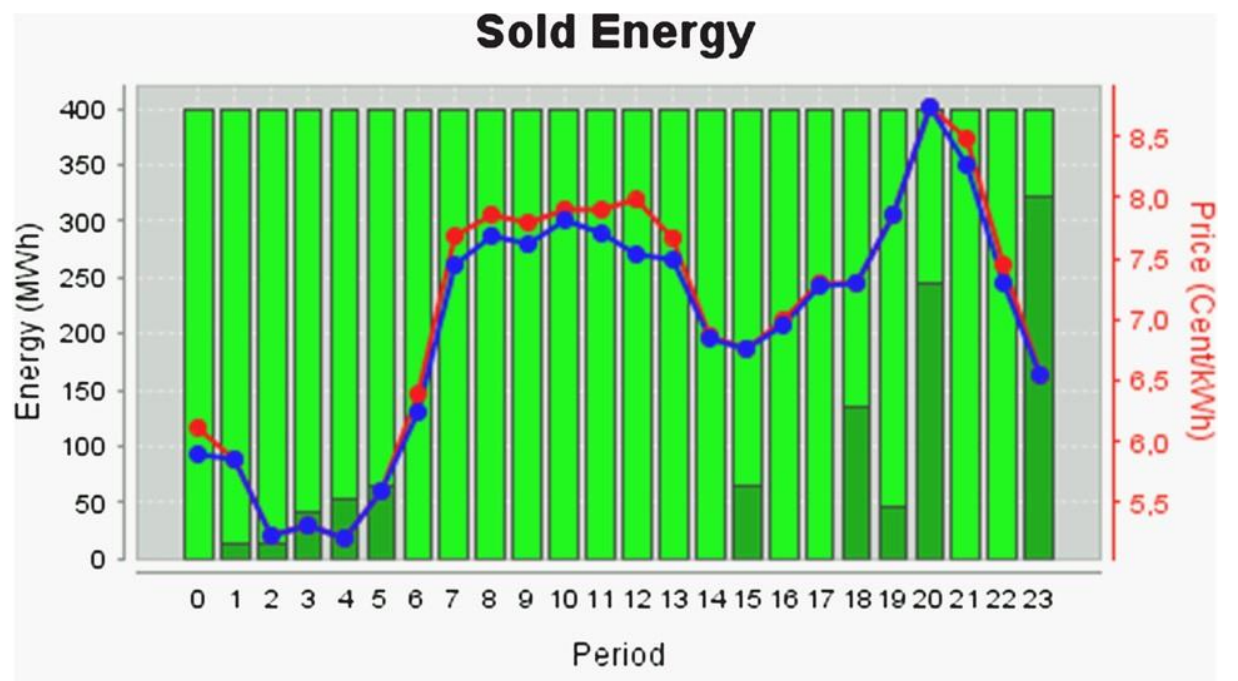

$\square \mathrm{BC} \square$ Pool $\square$ Unsold $\sim$ Price $\multimap$ Market Price 


\section{Sold Energy}

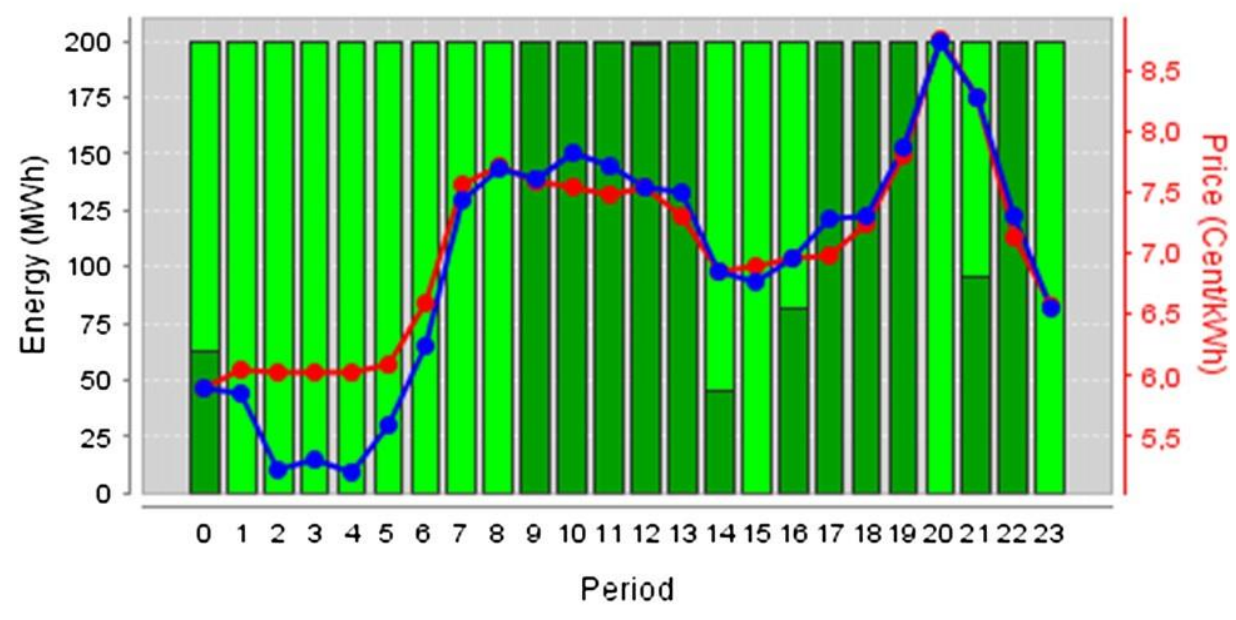

$\square B C \square$ Pool $\square$ Unsold $\bullet$ Price $\bullet-$ Market Price

Fig. 8. Seller 3 results.

\subsection{Market negotiation}

With the classification and aggregation processes completed, and so the VPPs aggregated players defined, the agents are ready for entrance in the market. We present a simulation referring to Wednesday, 29th October, 2008. The data used in this case study has been based on real data from the Spanish market, extracted from OMEL [24].

This simulation involves 7 buyers and 5 sellers (3 "normal" sellers and 2 of the VPPs considered before e VPP1 and VPP2). This group of agents was used with the intention of representing the Spanish reality, reduced to a smaller summarized group, containing the essential aspects of different parts of the market, in order to allow a better individual analysis and study the interactions and potentiality of each of those actors.

Agents' bids are defined as follows:

I. Buyer 1 e This buyer buys energy independently of the market price. The offer price is $18.30 \mathrm{cV} / \mathrm{kWh}$ (this value is much higher than average market price)
II. Buyer 2 e This buyer bid price varies between two fix prices, depending on the periods where it really needs to buy, and the ones in which the need is lower. The two prices are 10.00 and $8.00 \mathrm{cV} / \mathrm{kWh}$

III. Buyer 3 e This buyer bid considers the average prices of the previous 4 months with an increment of $0.5 \mathrm{cV} / \mathrm{kWh}$

IV. Buyer $4 \mathrm{e}$ This buyer bid considers the average prices of the previous 4 Wednesdays

V. Buyer 5 e This buyer bid considers the average prices of the previous 4 months

VI. Buyer 6 e This buyer bid considers the previous week average prices, considering only business days

VII. Buyer 7 e This buyer only buys energy if market prices are low (this agent's bid value is lower than average market

VIII. Seller 1 e As this seller needs to sell all the energy that he produces, the offer price is $0.00 \mathrm{cV} / \mathrm{kWh}$

IX. Seller 2 e This seller bidding price is based on the results of a neural network with an input layer of eight units, regarding the price and traded power for the same period of the

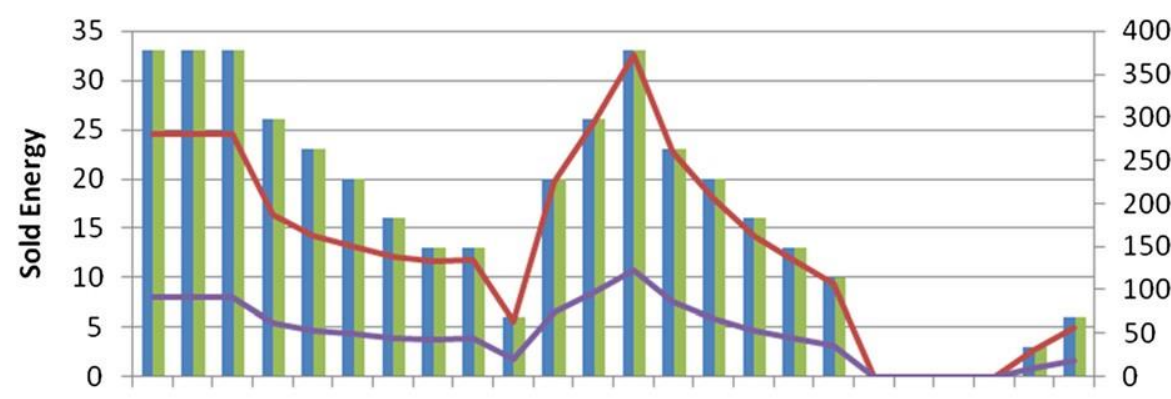

400

350

300

250

200

150

100

50

$\begin{array}{lllllllllllll}1 & 2 & 3 & 4 & 5 & 6 & 7 & 8 & 9 & 1011 & 12131415161718192021222324\end{array}$

Day Period
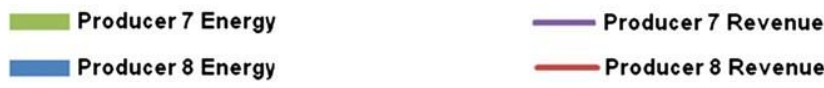

Fig. 9. Producer 7 and Producer 8 produced energy and remuneration. 
previous day, and the same weekdays of the previous three weeks. The neural network has an intermediate hidden layer of four units, and an output of one unit $e$ the predicted market price for the period in question

X. Seller 3 eBidding price based on linear regression over the historic OMEL data considering the price of all previous business days of October

XI. VPP 1 e This VPP offers a fix value along the day. The offer price is a low value, because of the VPP's need to sell, and guarantee the satisfaction of its aggregates. The offer value is $3.50 \mathrm{cV} / \mathrm{kWh}$

XII. VPP 2 e VPP 2 offer price is based on generation costs of cogeneration and on the total forecasted production.

The average prices have been computed based on July, August, September and October OMEL market prices.

Figs. 3 and 4 present Buyers' and Sellers' transactions for this case study.

Analyzing the considered VPPs' performance, we can see in Figs. 5 and 6 that both were able to sell all their available energy during theday.

Regarding the market price definition, Seller 2 is the agent with the higher influence, followed by Seller 3, as presented in Figs. 7 and 8 .

Seller $2^{0} \mathrm{~s}$ offer price curve is very close the market price in all of the periods, following the market price tendency during all day. This shows the neural network's adequability in predicting the prices, and catching its tendencies.

Concerning Seller 3, using the linear regression, its bid prices are also very close to the market price along the day, although with a little more variation comparing to Seller $2^{0} \mathrm{~s}$ bid curve.

These results indicate that both these strategies, with some adjustments to scale the prices a bit lower, could probably be very successful to define adequate strategies for bid definition with the propose of achieving the higher possible market prices, for a greater revenue, while guaranteeing the selling of all the available energy.

\subsubsection{Profit division}

Throughout the simulation, the VPP must divide its profits among its members, having the classification along with the amounts of energy sold as main factors to consider. Fig. 9 shows the amount of produced energy and the distribution of the profits among two of the members of VPP 2 (producers 7 and 8).

Analyzing Fig. 9, we may conclude that, despite having sold the same amounts of energy, Producer 8 presents a higher profit than Producer 7. That happens due to the much higher classification awarded to it. This proves the adequacy of the need of having the profits division based on the classification.

\section{Conclusions and future work}

This paper presented MASCEM, an electricity market simulator able to model market players and simulate their operation in the market. As market players are complex entities, each one with their own characteristics and needs, which must take their own decisions interacting with other players, a multi-agent architecture is used and proved to be adequate. This architecture includes learning capabilities, so that players are able to redefine their strategies according to their past experience (both real and simulated), considering also other agents' behaviour.

The main focus of this paper is the VPP formation, i.e. producers' aggregation, taking advantage on the proposed classification mechanism, and also on the study and implementation of some strategies to be used in the market by the intelligent agents. This allows the simulation of VPP operation, from production and load forecasting to real-time operation, after market clearance, while providing resources for the set of tasks VPP have to deal with, including reserve management, strategic bidding and producers' remuneration.

Concerning the proposed mechanisms, namely for classification and coalition entrance and management, they have proven to provide the VPP with a feature that allows it to better adequate its actions to the evolving status of the world, by recognizing the value that its actions can guarantee in the future. This proves to be a great improvement in the VPPs' operation, and so, it has positive impact in all the simulation entities, as it provides the means for the simulation to be more and more close to reality, providing the scenarios we need to further study and adapt the players to the electricity market constantly changing reality.

Relative to the players' strategies in negotiating in the market, we can conclude that, from the performed studies, there are strategies that allow the achievement of very good results, being able to catch the trends of the market prices. This suggests that a combination of several considered strategies, considering the distinct characteristics of each period, and the entities involved at each time can bring strategy formulation for bid prices to a whole new level. This is one of the issues we find essential as future work to improve this simulator in terms of intelligent behaviour.

Another important issue is improving the negotiations inside coalitions, to allow such negotiations to be fairer for all parts, and to consider different perspectives, i.e. the case of the negotiations between VPPs and candidates to justify an entrance to the coalition, or the candidate's choice of a coalition instead of another. To achieve that, we intend to take advantage of sophisticated protocols, where other Artificial Intelligence techniques, such as argumentation and multiple criteria based negotiations may be combined. Inside the context of multi-agent negotiation, an argument is seen as a piece of information able to influence other agents' negotiation stance and/or justify their own agent negotiation stance [25,26,27]. Argumentation can be excellent to justify possible choices and to convince other elements of the coalition that one alternative is better or worse than another.

\section{Acknowledgements}

The authors would like to acknowledge FCT, FEDER, POCTI, POSI, POCI, POSC, and COMPETE for their support to R\&D Projects and GECAD.

\section{References}

[1] Meeus L, Purchala K, Belmans R. Development of the internal electricity market in Europe. The Electricity Journal 2005;18(6):25e35.

[2] Electricity Advisory Committee. (, Keeping the lights on in a new world, http:// www.oe.energy.gov/eac.htm; January 2009.

[3] Praça I, Ramos C, Vale Z, Cordeiro M. MASCEM: a multi-agent system that simulates competitive electricity markets. IEEE Intelligent Systems 2003; 18(6):54e60. Special Issue on Agents and Markets.

[4] Vale Z, Pinto T, Praça I, Morais H. MASCEM e electricity markets simulation with strategically acting players. IEEE Intelligent Systems 2011;26(2):54e60. Special Issue on AI in Power Systems and Energy Markets.

[5] North M, Macal C. Managing business complexity: discovering strategic Solutions with agent-based modeling and simulation. Oxford University Press US; 2007.

[6] Li H, Tesfatsion L. Development of open source software for power market research: the AMES test bed. Journal of Energy Markets 2009;2(2):111e28.

[7] Somani A, Tesfatsion L. An agent-based test bed study of wholesale power market performance measures. IEEE Computational Intelligence Magazine 2008;3(4).

[8] Azevedo F, Vale Z, Oliveira P. A decision-support system based on particle swarm optimization for multi-period hedging in electricity markets. IEEE Transactions on Power Systems 2007;22(3):995e1003.

[9] Figueiredo V, Rodrigues F, Vale Z, Gouveia J. An electric energy consumer characterization framework based on data mining techniques. IEEE Transactions on Power Systems 2005;20(2):596e602. 
[10] Gutiérrez-Alcaraz G, Sheblé GB. Modeling energy market dynamics using discrete event system simulation. Energy October 2009;34(10):1467e76.

[11] Wang J, Zhou Z, Botterud A. An evolutionary game approach to analyzing bidding strategies in electricity markets with elastic demand. Energy May 2011;36(5):3459e67.

[12] Nguyen HT, Nabney IT. Short-term electricity demand and gas price forecasts using wavelet transforms and adaptive models. Energy September 2010; 35(9):3674e85.

[13] Koritarov V. Real-world market representation with agents: modeling the electricity market as a complex adaptive system with an agent-based approach. IEEE Power \& Energy Magazine; 2004:39e46.

[14] Pinto T, Vale Z, Morais H, Praça I, Ramos C. Multi-agent based electricity market simulator with VPP: conceptual and implementation issues. 2009 IEEE PES General Meeting; 2009

[15] Amjady N, Keynia F. Day-ahead price forecasting of electricity markets by mutual information technique and cascaded neuro-evolutionary algorithm. IEEE Transactions on Power Systems 2009;24:306e18.

[16] Chrysopoulos AC, Symeonidis AL, Mitktas PA. Improving agent bidding in power stock markets through a data mining enhanced agent platform. Agents and Data Mining Interaction; 2009:111e25. doi:10.1007/978-3-642-036033_9. Lecture Notes in Computer Science.

[17] Jain AK, Srivastava Strategic Bidding SC, Assessment Risk. Using genetic algorithm in electricity markets. International Journal of Emerging Electric Power Systems 2009;10(5). doi:10.2202/1553-779X.2161. article 1.
[18] Rahwan T, Jennings NR. Coalition structure generation: dynamic programming meets anytime optimization. In: Proc. 23rd conference on AI (AAAI). Chicago: E.U.A; 2008. p. 156e61.

[19] Praça I, Ramos C, Vale Z, Cordeiro M. Intelligent agents for negotiation and game-based decision support in electricity markets. International Journal of Engineering Intelligent Systems; 2003.

[20] Fudenberg D, Tirole J. Game theory. MIT Press; 1991.

[21] Ilic M, Galiana F, Lave L. Power systems restructuring: engineering and economics. Kluwer Academic Publishers Group; 1998.

[22] Morais H, Cardoso M, Castanheira L, Vale Z. A decision-support simulation tool for virtual power producers. International Conference on Future Power Systems; 2005

[23] Morais H, Cardoso M, Castanheira L, Vale Z, Praça I. Producers remuneration by virtual power producers. WSEAS Transactions on Power Systems July 2006; 1(7): 1358 e 65

[24] The OMEL. Operador del Mercado Ibérico de Energia website [Online]. Available, http://www.omel.es/; 2010.

[25] Jennings NR, Parsons S, Noriega P, Sierra C. On argumentation-based negotiation. In: Proc. Int. Workshop on Multi-agent Syst., Boston, USA; 1998

[26] Marreiros G, Santos R, Ramos C, Neves J. Context aware emotional model for group decision making. IEEE Intelligent Systems; 2010

[27] Ramchurn SD, Sierra C, Godo L, Jennings NR. Negotiating using rewards. Artificial Intelligence Journal 2007;171(10e15):805e37. 